\title{
Modulatory Effect of
}

\section{2-(4-Hydroxyphenyl)amino-1,4-naphthoquinone on Endothelial Vasodilation in Rat Aorta}

\author{
Javier Palacios, ${ }^{1}$ Fredi Cifuentes, ${ }^{2}$ Jaime A. Valderrama, ${ }^{1}$ Julio Benites, ${ }^{1}$ \\ David Ríos, ${ }^{1}$ Constanza González, ${ }^{1}$ Mario Chiong, ${ }^{3}$ Benjamín Cartes-Saavedra, ${ }^{3}$ \\ Carlos Lafourcade, ${ }^{4}$ Ursula Wyneken, ${ }^{4}$ Pamela González, ${ }^{5}$ Gareth I. Owen, ${ }^{5}$ \\ Fabián Pardo, ${ }^{6}$ Luis Sobrevia, ${ }^{6,7,8}$ and Pedro Buc Calderon ${ }^{1,9}$ \\ ${ }^{1}$ Departamento de Ciencias Químicas y Farmacéuticas, Facultad de Ciencias de la Salud, Universidad Arturo Prat, Iquique, Chile \\ ${ }^{2}$ Experimental Physiology Laboratory (EPhyL), Instituto Antofagasta, Universidad de Antofagasta, Antofagasta, Chile \\ ${ }^{3}$ Advanced Center for Chronic Diseases, Faculty of Chemical and Pharmaceutical Sciences, University of Chile, Santiago, Chile \\ ${ }^{4}$ Laboratorio de Neurociencias, Centro de Investigaciones Biomédicas, Universidad de los Andes, Monseñor Alvaro del Portillo 12.455 , \\ 7550000 Santiago, Chile \\ ${ }^{5}$ Facultad de Ciencias Biológicas y Centro UC Investigación en Oncología (CITO), Pontificia Universidad Católica de Chile, Chile \\ ${ }^{6}$ Cellular and Molecular Physiology Laboratory (CMPL), Division of Obstetrics and Gynecology, School of Medicine, \\ Faculty of Medicine, Pontificia Universidad Católica de Chile, 8330024 Santiago, Chile \\ ${ }^{7}$ Department of Physiology, Faculty of Pharmacy, Universidad de Sevilla, 41012 Seville, Spain \\ ${ }^{8}$ University of Queensland Centre for Clinical Research (UQCCR), Faculty of Medicine and Biomedical Sciences, \\ University of Queensland, Herston, QLD 4029, Australia \\ ${ }^{9}$ Toxicology and Cancer Biology Research Group, Université catholique de Louvain, Brussels, Belgium
}

Correspondence should be addressed to Pedro Buc Calderon; pedro.buccalderon@uclouvain.be

Received 27 May 2016; Revised 9 August 2016; Accepted 22 August 2016

Academic Editor: Gopi Kolluru

Copyright (C) 2016 Javier Palacios et al. This is an open access article distributed under the Creative Commons Attribution License, which permits unrestricted use, distribution, and reproduction in any medium, provided the original work is properly cited.

\begin{abstract}
The vascular endothelium plays an essential role in the control of the blood flow. Pharmacological agents like quinone (menadione) at various doses modulate this process in a variety of ways. In this study, Q7, a 2-phenylamino-1,4-naphthoquinone derivative, significantly increased oxidative stress and induced vascular dysfunction at concentrations that were not cytotoxic to endothelial or vascular smooth muscle cells. Q7 reduced nitric oxide (NO) levels and endothelial vasodilation to acetylcholine in rat aorta. It also blunted the calcium release from intracellular stores by increasing the phenylephrine-induced vasoconstriction when $\mathrm{CaCl}_{2}$ was added to a calcium-free medium but did not affect the influx of calcium from extracellular space. Q7 increased the vasoconstriction to $\mathrm{BaCl}_{2}\left(10^{-3} \mathrm{M}\right)$, an inward rectifying $\mathrm{K}^{+}$channels blocker, and blocked the vasodilation to $\mathrm{KCl}\left(10^{-2} \mathrm{M}\right)$ in aortic rings precontracted with $\mathrm{BaCl}_{2}$. This was recovered with sodium nitroprusside $\left(10^{-8} \mathrm{M}\right)$, a $\mathrm{NO}$ donor. In conclusion, $\mathbf{Q 7}$ induced vasoconstriction was through a modulation of cellular mechanisms involving calcium fluxes through $\mathrm{K}^{+}$channels, and oxidative stress induced endothelium damage. These findings contribute to the characterization of new quinone derivatives with low cytotoxicity able to pharmacologically modulate vasodilation.
\end{abstract}

\section{Introduction}

A functional vascular endothelium could have major clinical implications in pathologies such as cardiovascular disease, diabetes, and cancer $[1,2]$. Previous studies have shown that the treatment with quinone-related compounds (i.e., 1,4naphthoquinone derivatives) can impair $[3,4]$ or improve vascular functions [5]. The underlying mechanism(s) of quinone on vascular functions are still not fully understood. For instance, the observed decreased relaxation and increased 
contraction of blood vessels induced by menadione was partly explained by inhibition of NO pathway via the formation of reactive oxygen species (ROS). The hypotension and vasorelaxation effects of naphthoquinone-oxime were suggested to be due to activation of soluble guanylate cyclase (sGC), $\mathrm{K}^{+}$channels, and via NO pathway [6].

Quinones are widely distributed molecules in nature, and they are found as endogenous compounds of biological importance (i.e., coenzyme Q in mitochondrial electron chain; vitamin $\mathrm{K}_{2}$ in blood coagulation) in humans. Numerous therapeutic drugs, in particular antitumor compounds, are quinone-bearing molecules including anthracyclines (doxorubicin, mitoxanthrone, and daunarubicin), benzoquinones (mitomycin $\mathrm{C}$, geldanamycin), orthonaphthoquinones like $\beta$-lapachone, and several synthetic compounds which are currently under clinical trials using 1,4naphthoquinone as pharmacophore group [6-9]. They are reported to cause cytotoxic effects through varied mechanisms such as DNA intercalation, reductive alkylation of biomolecules, and ROS formation through a redox-cycling reaction [10-12]. Regarding this latter mechanism, quinone reduction by 1 or 2 electrons from NADPH-cytochrome $\mathrm{P} 450$ reductase leads to a semiquinone free radical which is oxidized back to the former quinone in the presence of molecular oxygen, while oxygen is reduced to superoxide anion [13]. This redox-cycling leads to the formation of other ROS, such as hydrogen peroxide and hydroxyl radicals [14, 15]. Based on this redox-cycling property, several quinones have been used as therapeutic agents against several diseases and pathologies [16-18]. As such they induced cell death by either apoptosis or necrosis, inhibiting cancer cells growth [19-21]. They also activated a senescence program leading to cell cycle arrest [22, 23].

Our observations were that one arylamino-naphthoquinone derivative, namely, Q7 [2-(4-hydroxyphenyl)amino-1,4naphthoquinone], was able to provoke a drop in ATP cell content and inhibit cancer cell proliferation [24]. This inhibition induced cancer cells senescence [10], reduction of DNA damage, and inhibition of in vivo tumor growth [11]. It also leads to an inhibition of in vivo tumor progression by triggering apoptosis, cell cycle arrest, suppression of HIF-1, and uncoupling glycolytic metabolism [25]. All these effects have been attributed to its ability to generate ROS through quinone redox-cycling. Meanwhile, it has been reported that some naphthoquinone derivatives are potent inhibitors of endothelium-dependent vasodilation via an inhibition of endothelial NOS, possibly by interacting with the reductase domain of the enzyme $[4,26]$. Indeed, it has been reported that oxidative stress enhances vascular reactivity, most likely by increasing the formation of ROS and decreasing the availability of nitric oxide [27, 28].

Based on these facts and due to the critical role of vascular functions in different pathologies, we have explored new biological activities of $\mathbf{Q 7}$ as to be used beyond the context of cancer, especially as it interferes with oxidative stress and vascular function (reactivity and endothelium), an integral complex involved in the survival or death of these cancerous cells.

\section{Materials and Methods}

2.1. Cell Culture. Human umbilical vein endothelial cells (HUVEC) were isolated by collagenase $0.25 \mathrm{mg} / \mathrm{mL}$, Collagenase Type II from Clostridium histolyticum (Boehringer, Mannheim, Germany) digestion from umbilical cords obtained at birth from pregnancies and cultured $\left(37^{\circ} \mathrm{C}, 5 \% \mathrm{CO}_{2}\right)$ in $1 \%$ gelatin-coated petri dishes up to passage 2 in medium 199 (M199; Life Technologies, Carlsbad, CA, USA) containing $5 \mathrm{mmol} / \mathrm{L}$ D-glucose, $10 \%$ new born bovine serum, $10 \%$ fetal bovine serum (FBS), $3.2 \mathrm{mmol} / \mathrm{L} \mathrm{L}$-glutamine, and $100 \mathrm{U} / \mathrm{mL}$ penicillin-streptomycin (primary culture medium). A7r5 cells, a vascular smooth muscle cell (VSMC) line originally derived from embryonic rat aorta, were purchased from the American Type Culture Collection (ATCC). They were cultured in Dulbecco's Modified Eagle Medium (DMEM; Invitrogen, NY, USA, Sigma-Aldrich) supplemented with $10 \%$ FBS and $2 \times 10^{-3} \mathrm{M}$ pyruvate. Prior to experiments, $80-90 \%$ confluent A7r5 cells were serum-starved.

2.2. MTS Reduction Assay. Briefly, cells (50-60\% confluence) were seeded in 96-well plates. Cells were incubated at $37^{\circ} \mathrm{C}$ in a humidified 5\% $\mathrm{CO}_{2} / 95 \%$ air mixture. HUVECs and $\mathrm{A} 7 \mathrm{r} 5$ vascular smooth cell line were incubated in the absence or in the presence of Q7 $\left(10^{-7} \mathrm{M}, 10^{-6} \mathrm{M}, 10^{-5} \mathrm{M}\right.$, and $\left.10^{-4} \mathrm{M}\right)$ for $48 \mathrm{~h}$, and cytotoxicity was determined using the MTS [3-(4,5-dimethylthiazol-2-yl)-5-(3carboxymethoxyphenyl)2-(4-sulfophenyl)-2H-tetrazolium] reduction assay. Cell Titer 96 ${ }^{\circledR}$ AQueous One Solution Cell Proliferation Assay, Promega, WI, USA. Cyclophosphamide $\left(10^{-4} \mathrm{M}\right)$ was used as negative control and $10^{-5} \mathrm{M}$ epirubicin (anthracycline drug used for chemotherapy) as positive control. The MTS and Q7 were dissolved in vehicle (DMSO) at final concentration less than $0.1 \%$. All the assays were performed in quintupled and in 3 independent experiments. The cytotoxicity was calculated in accordance with the formula: cytotoxicity $(\%)=(1-($ absorbance sample/absorbance control $)) \times 100$. The absorbance of sample was determined in the absence (vehicle; control) or in the presence of Q7. The absorbance was measured with a microplate reader (Infinite 200 PRO; Tecan, Switzerland) at $490 \mathrm{~nm}$.

2.3. Animals. Male and female Sprague-Dawley rats (4-5 weeks of age, 120-180 g) from the breeding colony at the Antofagasta University were used for this study. All rats were housed in a temperature-controlled, light-cycled (08:0020:00 hours) room with ad libitum access to drinking water and standard rat chow (Champion, Santiago). The assays were conducted according to the Guide for the Care and Use of Laboratory Animals published by the U.S. National Institutes of Health (NIH Publication revised 2013), and the local animal research committee approved the experimental procedure used in the present study.

2.4. Isolation of Aortic Rings. Rats were sacrificed through cervical dislocation. The thoracic aorta was quickly excised and placed in cold $\left(4^{\circ} \mathrm{C}\right)$ physiological Krebs-Ringer bicarbonate buffer $(\mathrm{KRB})$ containing $\left(\times 10^{-3} \mathrm{M}\right) 4.2 \mathrm{KCl}, 1.19$ 
$\mathrm{KH}_{2} \mathrm{PO}_{4}, 120 \mathrm{NaCl}, 25 \mathrm{Na}_{2} \mathrm{HCO}_{3}, 1.2 \mathrm{MgSO}_{4}, 1.3 \mathrm{CaCl}_{2}$, and 5 D-glucose ( $\mathrm{pH}$ 7.4). Rings ( $3-5 \mathrm{~mm}$ and $2-4 \mathrm{mg}$ ) were prepared after connective tissue was cleaned out from the aorta, taking special care to avoid endothelial damage. Aortic rings were equilibrated for $40 \mathrm{~min}$ at $37^{\circ} \mathrm{C}$ by constant bubbling with $95 \% \mathrm{O}_{2}$ and $5 \% \mathrm{CO}_{2}$.

2.5. Vascular Reactivity Experiments. Aortic rings of native animals were incubated $(30 \mathrm{~min})$ and perfused acutely with Q7 $\left(10^{-6} \mathrm{M}\right.$ and $\left.10^{-5} \mathrm{M}\right)$ in the organ bath. The aortic rings from the same animal were studied in duplicate, using different vasoactive substances (phenylephrine [PE], acetylcholine [ACh], sodium nitroprusside [SNP], $\mathrm{KCl}$ ). The rings were mounted on two 25-gauge stainless steel wires; the lower one was attached to a stationary glass rod and the upper one was attached to an isometric transducer (Radnoti, Monrovia, California). The transducer was connected to a PowerLab $8 / 35$ (Colorado Springs CO) for continuous recording of vascular tension using the LabChart 8 computer program (ADS Instruments).

After the equilibration period, the aortic rings were stabilized by 2 successive near-maximum contractions with $\mathrm{KCl}\left(6 \times 10^{-2} \mathrm{M}\right)$ for $10 \mathrm{~min}$. The passive tension on aorta was $1.0 \mathrm{~g}$, which was determined to be the resting tension for obtaining maximum active tension induced by $6 \times 10^{-2} \mathrm{M}$ $\mathrm{KCl}$. Ten min after contraction with phenylephrine (PE; $10^{-6} \mathrm{M}$ ), cumulative concentrations of acetylcholine (ACh) were added to the medium $\left(10^{-8}\right.$ to $\left.10^{-5} \mathrm{M}\right)$. Similar protocols were repeated with SNP $\left(10^{-8}\right.$ to $\left.10^{-6} \mathrm{M}\right)$. To study the role of extracellular calcium, experiments were performed with a calcium-free KRB containing $\left(\times 10^{-3} \mathrm{M}\right)$ 1.0 EGTA, 4.2 $\mathrm{KCl}, 1.19 \mathrm{KH}_{2} \mathrm{PO}_{4}, 125 \mathrm{NaCl}, 25 \mathrm{Na}_{2} \mathrm{HCO}_{3}, 1.2 \mathrm{MgSO}_{4}$, and 5 D-glucose $(\mathrm{pH}$ 7.4). The aortic rings were preincubated in a KRB with calcium for $30 \mathrm{~min}$; then the KRB was changed with KRB without calcium for $5 \mathrm{~min}$ before PE $\left(10^{-6} \mathrm{M}\right)$ was added. Five min after contraction with $\mathrm{PE}$ $\left(10^{-6} \mathrm{M}\right)$, cumulative concentrations of $\mathrm{CaCl}_{2}(0.1$ to $1.0 \times$ $10^{-3} \mathrm{M}$ ) were added to the medium. In other experiments the contraction was induced by $10^{-3} \mathrm{M} \mathrm{BaCl}_{2}$ for $10 \mathrm{~min}$ and then relaxed with $10^{-2} \mathrm{M} \mathrm{KCl} . \mathrm{BaCl}_{2}$ is used because it increases vasoconstriction by blocking of inward rectifying $\mathrm{K}^{+}$channels [29-31], thus depolarizing the plasma membrane.

2.6. Lipid Peroxidation. Thiobarbituric acid reactive substances (TBARS) were measured in rat aorta homogenates. Samples of homogenates $(500 \mu \mathrm{L} ; 10 \pm 1.4 \mathrm{mg}$ protein $/ \mathrm{mL})$ were incubated with vehicle and Q7 $\left(10^{-6}-10^{-4} \mathrm{M}\right)$ for $30 \mathrm{~min}$ and then centrifuged at $3000 \times \mathrm{g}$ for $20 \mathrm{~min}$ at $4^{\circ} \mathrm{C}$. A $100 \mu \mathrm{L}$ aliquot of the supernatant was mixed with $200 \mu \mathrm{L}$ of $10 \%$ trichloroacetic acid (TCA) and $4 \%$ butylated hydroxytoluene. The mixture was then centrifuged and $140 \mu \mathrm{L}$ of supernatant (in duplicate) was mixed with thiobarbituric acid (0.67\%) and heated for $1 \mathrm{~h}$ at $95^{\circ} \mathrm{C}$. After cooling to room temperature, $280 \mu \mathrm{L}$ of butanol-pyridine $(15: 1)$ was added. After centrifugation $(3000 \times \mathrm{g}, 20 \mathrm{~min})$ the absorbance was measured at $532 \mathrm{~nm}$.
2.7. Nitrite/Nitrate Assay. The production of NO by a segment of the rat aorta (in native rats) was measured by nitrite accumulation using the Griess reaction method [32]. Aortic rings were incubated in KRB constantly bubbled with $95 \% \mathrm{O}_{2}$ and $5 \% \mathrm{CO}_{2}$ for $40 \mathrm{~min}$ at $37^{\circ} \mathrm{C}$. $\mathrm{KRB}$ containing $\left(\times 10^{-3} \mathrm{M}\right) 4.2 \mathrm{KCl}, 1.19 \mathrm{KH}_{2} \mathrm{PO}_{4}, 120 \mathrm{NaCl}, 25 \mathrm{Na}_{2} \mathrm{HCO}_{3}$, $1.2 \mathrm{MgSO}_{4}, 1.3 \mathrm{CaCl}_{2}$, and $5 \mathrm{D}$-glucose (pH 7.4). Aortic rings were incubated at $37^{\circ} \mathrm{C}$ for $30 \mathrm{~min}$ with saline, $\mathrm{ACh}$ $\left(10^{-5} \mathrm{M}\right)$ or the combination of ACh $\left(10^{-5} \mathrm{M}\right)$ and $\mathrm{Q7}\left(10^{-5} \mathrm{M}\right)$ or ACh $\left(10^{-5} \mathrm{M}\right)$ plus $\mathrm{N}_{\mathrm{w}}$-nitro-L-arginine methyl ester (LNAME; $\left.10^{-4} \mathrm{M}\right)$. At the end of incubation, samples were collected and nitrate reduction was carried out with $\mathrm{Zn}$ dust for $30 \mathrm{~min}$ at room temperature. Total nitrites in each sample were determined by the addition of $1 \%$ sulfanilamide, followed by $0.1 \% \mathrm{~N}$-(1-naphthyl) ethylenediamine (NED) in $5 \%$ phosphoric acid. The absorbance was measured with a microplate reader (Infinite $200 \mathrm{PRO}$; Tecan, Switzerland) at $550 \mathrm{~nm}$. Nitrite concentration was expressed as $\mu \mathrm{M} / \mathrm{mg}$ tissue and calculated from a standard curve with sodium nitrite.

2.8. L-Citrulline Assay. NOS activity was determined by incubation of HUVECs with $10^{-4} \mathrm{M} \mathrm{L}$-arginine and $9 \times 10^{-6}$ $\mathrm{Ci} / \mathrm{mL} \mathrm{L}-\left[{ }^{3} \mathrm{H}\right]$ arginine $\left(30\right.$ minutes, $\left.37^{\circ} \mathrm{C}\right)$ in the absence or presence of $10^{-4} \mathrm{M}$ L-NAME (a NOS inhibitor). In addition, $10^{-5} \mathrm{M}$ Q7 was used. HUVECs were incubated in HEPES buffer containing $\left(\times 10^{-3} \mathrm{M}\right) 50$ HEPES, $100 \mathrm{NaCl}, 5 \mathrm{KCl}, 2.5$ $\mathrm{CaCl}_{2}$, and $1 \mathrm{MgCl}_{2}\left(\mathrm{pH}\right.$ 7.4). The fraction of L- $\left.{ }^{3} \mathrm{H}\right]$ citrulline formation inhibited by L-NAME was considered NOS activity [33]. Digested cells (95\% formic acid) were passed through an ion-exchange resin Dowex-50W 5 (50X8-200) and L$\left[{ }^{3} \mathrm{H}\right]$ citrulline was determined in $\mathrm{H}_{2} \mathrm{O}$ eluate as described [34]. NOS activity was calculated by subtracting L-NAMEinsensitive L-citrulline from the total L-citrulline.

2.9. Determination of Intracellular Calcium in Culture Cell. A7r5 cells were cultured in $35 \mathrm{~mm}$ culture dish for confocal microscopy (ibidi, Germany). The cells were washed with Krebs with calcium containing $\left(\times 10^{-3} \mathrm{M}\right) 140 \mathrm{NaCl}, 5 \mathrm{KCl}$, $1 \mathrm{CaCl}_{2}, 1 \mathrm{MgCl}_{2}, 10$ HEPES, and 5.6 glucose, $\mathrm{pH}$ 7.4. Then, they were loaded with $10^{-5} \mathrm{M}$ Fluo-3-AM for $25 \mathrm{~min}$ at $37^{\circ} \mathrm{C}$ and then were again washed with Krebs without calcium containing $\left(\times 10^{-3} \mathrm{M}\right) 145 \mathrm{NaCl}, 5 \mathrm{KCl}, 1 \mathrm{MgCl}_{2}, 10$ HEPES$\mathrm{Na}$, and 5.6 glucose, $\mathrm{pH}$ 7.4. In Krebs free-calcium $5 \times 10^{-5} \mathrm{M}$ BAPTA-AM was used. The cells were preincubated in Krebs without calcium for $5 \mathrm{~min}$ before PE $\left(10^{-6} \mathrm{M}\right)$ was added, and then $10^{-3} \mathrm{M}$ of $\mathrm{CaCl}_{2}$ was added to the medium. The intensity of $\mathrm{Ca}^{2+}$ fluorescence was measured with a laser scanning confocal microscope (Leica TCS SP8, Concord, ON, Canada) and fluorescence was recorded every 5 seconds. Analysis involved determination of pixels assigned to each cell using Image J software. The average pixel value allocated to each cell was obtained with excitation at $506 \mathrm{~nm}$ and corrected for background.

2.10. Chemicals. The following drugs were used in this study: L-phenylephrine hydrochloride (PE; Sigma-Aldrich, St. Louis, Mo), acetylcholine chloride (ACh; Sigma-Aldrich, 
<smiles>O=C(C=C(Nc1ccc(O)cc1)C(=O)c1ccccc1)c1ccccc1</smiles>

FIGURE 1: Chemical structure of 2-[(4-hydroxyphenyl)amino]-1,4-naphthoquinone (Q7).

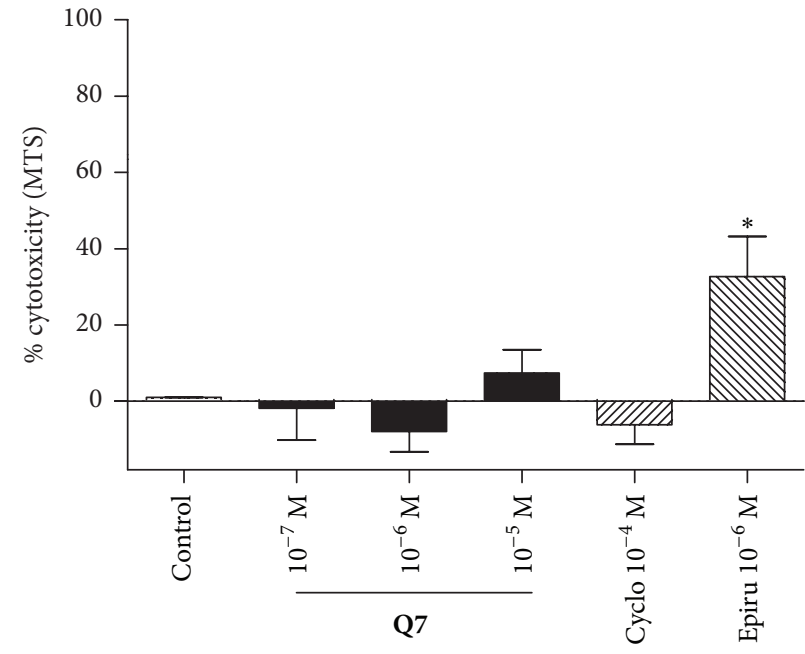

(a)

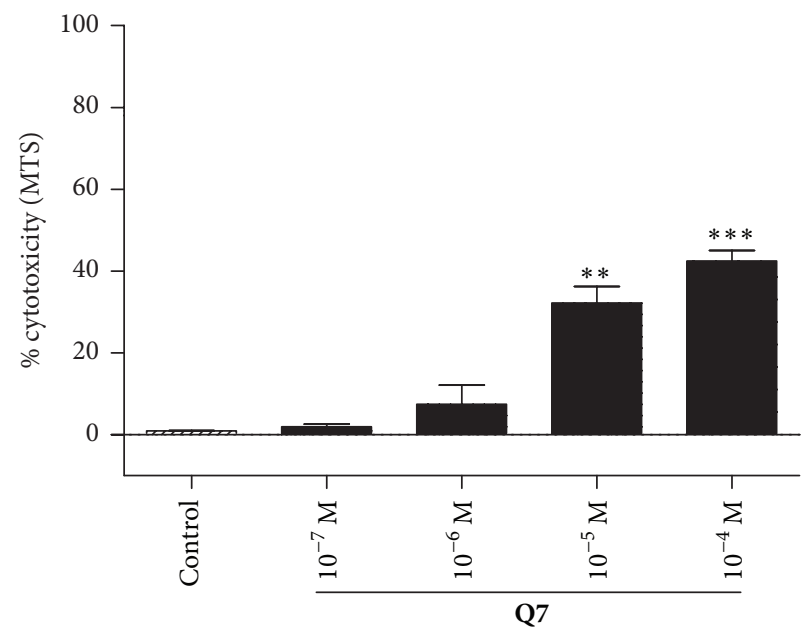

(b)

FIGURE 2: Q7 does not induce cell death. The results show that Q7 cytotoxicity was low or negligible on a vascular endothelial cell or vascular smooth muscle cell line, respectively. Q7 cytoxicity was determined by MTS assay. Human umbilical vein endothelial cells (HUVEC) (a) and A7r5 vascular smooth cell line (b) were incubated in the absence or in the presence of Q7 $\left(10^{-7}\right.$ to $\left.10^{-4} \mathrm{M}\right)$ for 48 h. Cyclophosphamide (Cyclo; $10^{-4} \mathrm{M}$ ) was used as negative control and epirubicin (Epirub; $10^{-5} \mathrm{M}$ ) as positive control. The cells were seeded at $50 \%$ density. Data are the average \pm SEM of 4 independent experiments; ${ }^{*} p<0.05 ;{ }^{* *} p ;{ }^{* * *} p<0.001$ versus control.

Munich, Germany), sodium nitroprusside (SNP; Merck, Darmstadt, Germany), barium chloride dihydrate $\left(\mathrm{BaCl}_{2}\right.$; Sigma-Aldrich, St. Louis, MO), sulfanilamide (Sigma-Aldrich, St. Louis, MO), N-(1-naphthyl)ethylenediamine(NED; Sigma-Aldrich, St. Louis, MO), tetramethoxypropane (Sigma-Aldrich, St. Louis, Mo), thiobarbituric acid (Merck, Darmstadt, Germany), butylated hydroxytoluene (Merck, Darmstadt, Germany), $\mathrm{N}_{\mathrm{w}}$-nitro-L-arginine methyl ester (L-NAME; Sigma-Aldrich, St. Louis, MO), and BAPTAAM (Invitrogen, USA). Drugs were dissolved in distilled deionized water. The solutions in Krebs-Ringer bicarbonate (KRB) were freshly prepared before each experiment. Figure 1 shows chemical structure of 2-[(4-hydroxyphenyl)amino]-1,4-naphthoquinone (Q7; $265.07 \mathrm{~g} / \mathrm{mol})$; it was synthesized by amination of 1,4-naphthoquinone with 4-hydroxyphenylamine, under aerobic conditions, using $\mathrm{CeCl}_{3} \cdot 7 \mathrm{H}_{2} \mathrm{O}$ as the Lewis acid catalyst as previously reported [35].

2.11. Statistical Analysis. Values are expressed as mean \pm standard error of the mean; $n$ denotes the number of animals studied. One- or two-way analysis of variance (ANOVA) was carried out to detect significant differences, followed by
Bonferroni post-tests to compare all groups. A $p$ value of $<0.05$ was considered statistically significant.

\section{Results}

3.1. Cytotoxicity of $\mathbf{Q 7}$ on Vascular Endothelial Cell Line and Vascular Smooth Muscle. Because oxidative stress is associated with cell death, the effect of Q7 on the viability of HUVEC and the vascular smooth muscle cell line A7r5 was assessed (Figure 2). After $48 \mathrm{~h}$ of incubation, the cytotoxicity in presence of $10^{-5} \mathrm{M}$ Q7 did not significantly increase in endothelial cells $(1.00 \pm 0.05 \%$ in control versus $7.39 \pm$ $6.14 \%$ with $10^{-5} \mathrm{M}$ Q7) and increased significantly in vascular smooth muscle cells $(0.97 \pm 0.03 \%$ in control versus $32.20 \pm$ $4.04 \%$ with $10^{-5} \mathrm{M}$ Q7; $\left.p<0.01\right)$. As expected, no significant cytotoxicity was observed with the chemotherapy cyclophosphamide $\left(10^{-4} \mathrm{M}\right)$, which is activated only after metabolism in the liver and thus is inactive in cell culture.

3.2. Q7 Induces Oxidative Stress in Rat Aorta and Decreases Endothelial NO Production in Rat Aorta. We conducted experiments to evaluate oxidative stress revealed by Q7mediated lipid oxidation in rat aorta tissue. TBARS assay 


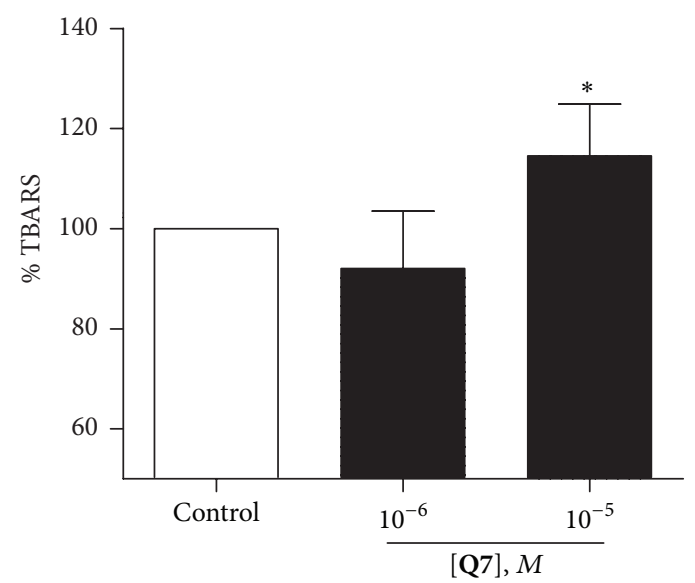

(a)

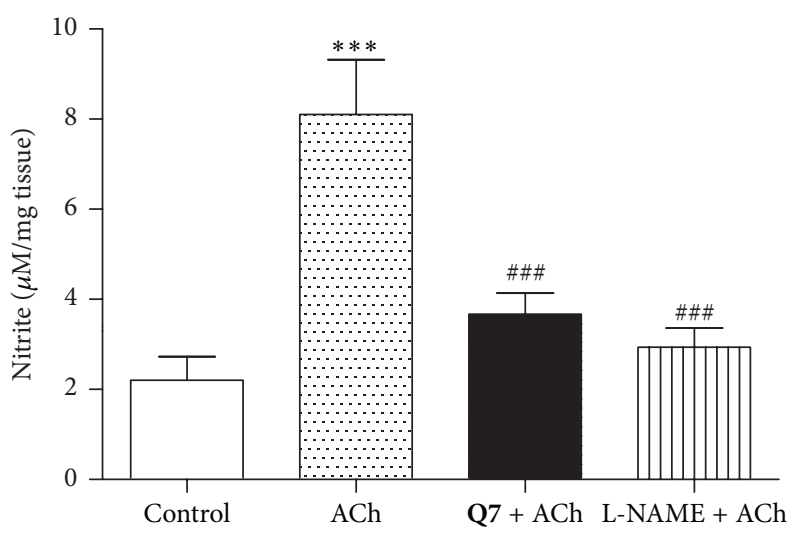

(b)

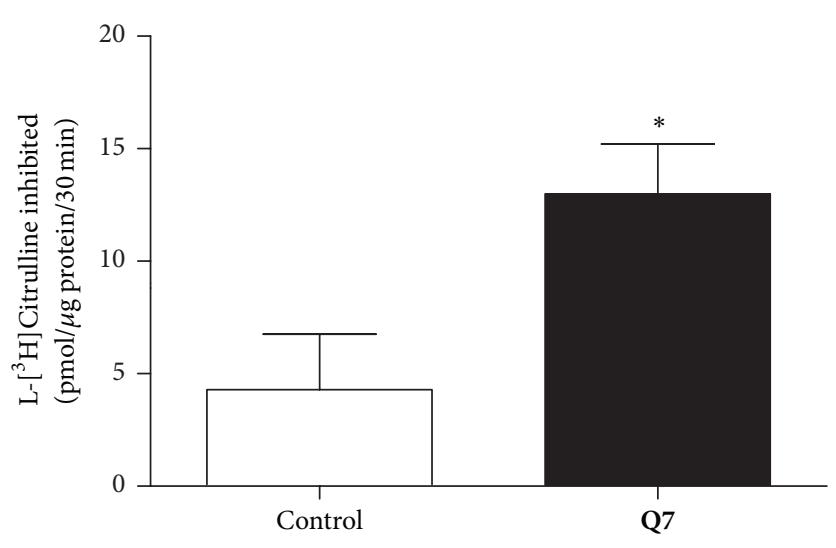

(c)

FIGURE 3: Q7 produces oxidation of lipids and decreases endothelial NO. Depicting oxidative stress revealed by Q7-mediated lipid oxidation and a change of endothelial NO release in rat aorta tissue. The rat aorta homogenate determination of TBARS in presence of Q7 $\left(10^{-6}\right.$ and $10^{-5} \mathrm{M}$ ) was measured as \% with respect to control (a). Significant differences were found between $10^{-5} \mathrm{M} \mathrm{Q7}$ versus control or $10^{-6} \mathrm{M}$ of Q7 $\left({ }^{*} p<0.05\right)$. The production of NO by a segment of the rat aorta was measured by the accumulation of nitrite using Griess reaction method (b): the aortic rings were incubated with vehicle (control), $10^{-5} \mathrm{M} \mathrm{ACh}, 10^{-5} \mathrm{M} \mathrm{Q7}$ plus $10^{-5} \mathrm{M} \mathrm{ACh}$, and $10^{-5} \mathrm{M} \mathrm{ACh}$ plus $10^{-4} \mathrm{M}$ L-NAME. Data are the average \pm SEM of 5 independent experiments. ${ }^{* * *} p<0.001$ versus control; ${ }^{\# \# \#} p<0.001$ versus ACh; effect of $\mathbf{Q} 7$ on eNOS activity and production of endothelial NO (c). The production of NO was determined indirectly by the formation of L-citrulline in the reaction catalyzed by eNOS in HUVEC. The results are mean standard error of the mean. Asterisk indicates statistically significant differences compared to the control $\left({ }^{*} p<0.05 ; n=3\right)$.

was used as an index of lipid peroxidation. As shown in Figure 3(a), Q7 $\left(10^{-5} \mathrm{M}\right)$ increased the formation of TBARS by $114 \pm 5 \%$ as compared to control (vehicle).

To unravel the modulatory effects on mechanisms involved in vasodilation, NO formation in rat aorta was assessed by measuring the production of nitrites using the Griess reaction. The aortic rings were incubated with vehicle, ACh $\left(10^{-5} \mathrm{M}\right)$, and Q7 $\left(10^{-5} \mathrm{M}\right)+\mathrm{ACh}\left(10^{-5} \mathrm{M}\right)$ for $30 \mathrm{~min}$. Figure 3(b) shows that the preincubation with Q7 significantly decreased the formation of endothelial $\mathrm{NO}(8.1 \pm 1.2$ nitrite $\mu \mathrm{M} / \mathrm{mg}$ tissue with ACh versus $3.7 \pm 0.5$ nitrite $\mu \mathrm{M} / \mathrm{mg}$ tissue with Q7 + ACh, $p<0.01)$. The preincubation with LNAME also decreased significantly the production of nitrites $(2.9 \pm 0.4$ nitrite $\mu \mathrm{M} / \mathrm{mg}$ tissue with L-NAME $+\mathrm{ACh}, p<$ $0.01)$.

We measured eNOS activity in presence of $\mathbf{Q 7}$ by the formation of L-citrulline in the reaction catalyzed by eNOS in HUVEC (Figure 3(c)). The concentration of L-citrulline formed is directly proportional to the NO concentration formed and eNOS activity. We showed that Q7 $\left(10^{-5} \mathrm{M}\right)$ increased the concentration of L-citrulline in HUVEC (4.29 $\pm 2.46 \mathrm{pmol} / \mu \mathrm{g}$ protein control, $12.99 \pm 2.22 \mathrm{pmol} / \mu \mathrm{g}$ protein with $10^{-5} \mathrm{M}$ Q7; $\left.p<0.05\right)$.

To test whether decreased or increased NO might have an effect on vasodilation, we tested the modulatory effect of Q7 on ACh-induced vasodilation and PE-induced vasoconstriction (Figures 4 and 5).

3.3. Endothelial Vasodilation of Rat Aortic Rings Induced by ACh Is Impaired by Q7. To confirm that Q7 impairs endothelial dependent vasodilation via a NO pathway, further experiments were conducted in $\mathrm{PE}\left(10^{-6} \mathrm{M}\right)$ precontracted aortas and doses of either ACh $\left(10^{-8}-10^{-5} \mathrm{M}\right.$; Figures $\left.5(\mathrm{a})-5(\mathrm{c})\right)$ or 


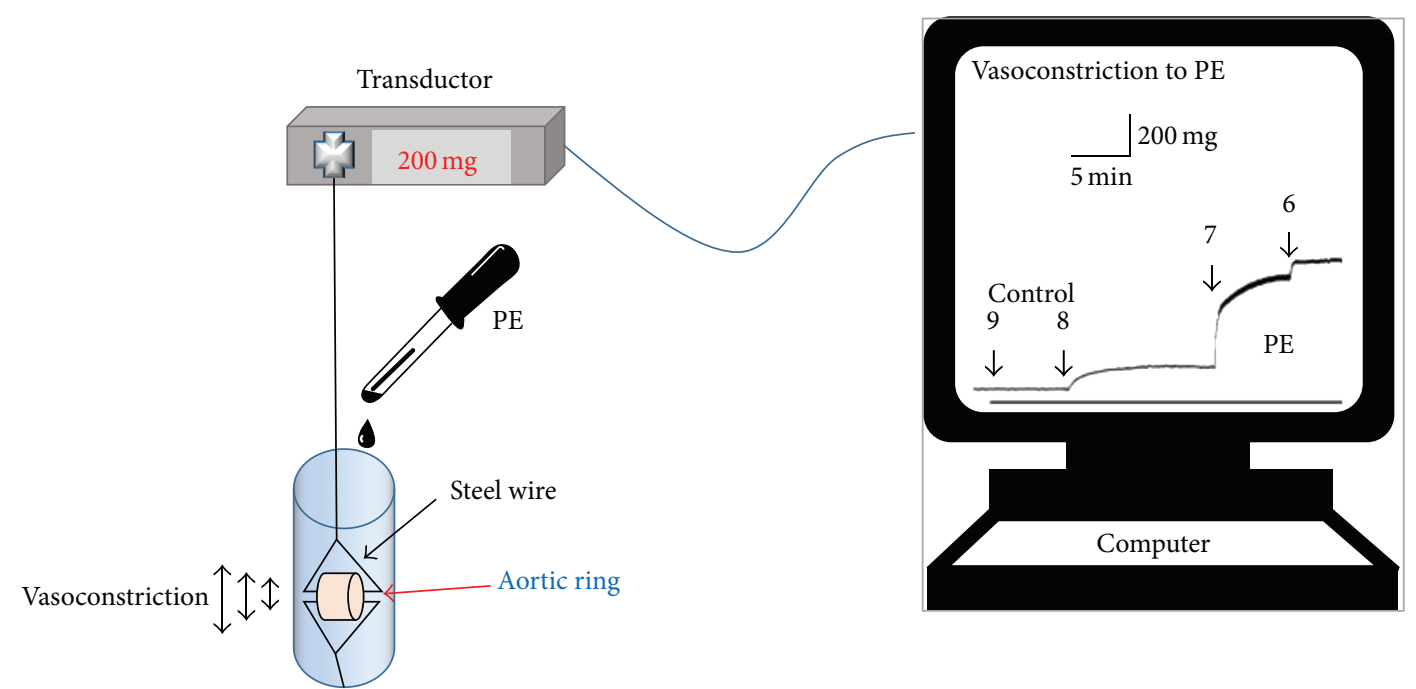

Organ bath:

(i) Buffer: $\mathrm{pH} 7.4$

(ii) $95 \% \mathrm{O}_{2}$ and $5 \% \mathrm{CO}_{2}$

(iii) $37^{\circ} \mathrm{C}$

FIGURE 4: Vascular reactivity experimental setup. Aortic ring was mounted on two steel wires; the upper one was attached to an isometric transducer. An equilibration period and stabilization with $\mathrm{KCl}$ were allowed, and the tissue was washed two times with fresh $\mathrm{KRB}$. Then, we performed the protocol of the experiment; we added different concentrations of PE, which caused vasoconstriction of aortic ring. To finish, data were registered in the computer. The increase of the trace of the screen indicates vasoconstriction to PE, while the decrease of the trace indicates vasodilatation of the aortic ring.

SNP $\left(10^{-10}-10^{-6} \mathrm{M}\right.$; Figure $\left.5(\mathrm{~d})\right)$ were increased. As shown in Figures 5(b) and 5(c), preincubation for $30 \mathrm{~min}$ with Q7 $\left(10^{-5} \mathrm{M}\right)$ results in a significant decrease of ACh-mediated vasodilation of intact aortic rings: $115 \pm 2 \%$ control versus $73 \pm 3 \%$ with $10^{-5} \mathrm{M}$ Q7 $\left(10^{-5} \mathrm{M}\right.$ ACh; $\left.p<0.05\right)$. This finding suggests that $\mathbf{Q 7}$ decreases the endothelial nitric oxide, ACh-induced, which agrees with decreased production of nitrites observed in previous experiments. Nevertheless, by applying the same experimental protocol and using a NOdonor compound, namely, SNP, a vasodilation of $100 \%$ was observed even in the presence of $10^{-5} \mathrm{M}$ Q7 (Figure 5(d)). This indicates that the reduction of vasodilation can be overcome by NO; therefore, Q7 only impairs the endothelial response and there was no response of vascular smooth muscle.

In the next experiments, we studied if the decreased vasodilation should be accompanied by reduced intracellular calcium in precontracted aorta with PE.

3.4. Effect of $\mathbf{Q 7}$ on the Calcium Homeostasis in A7r5 Cells. To investigate if the contractile response of $\mathrm{PE}$ in presence of $\mathbf{Q 7}$ could be modulated by calcium released from intracellular stores, further experiments were conducted with PE in A7r5 cells in a calcium-free medium. Figure 6 shows that this situation, $10^{-5} \mathrm{M}$ Q7, drastically blunted the release of calcium from intracellular stores in response to $10^{-6} \mathrm{M} \mathrm{PE}$, but it however, did not blunt the increase of intracellular calcium when $1 \mathrm{mM} \mathrm{CaCl}_{2}$ was added to extracellular space.
In order to gain insight into potential role of Q7 on vascular reactivity, we repeat a similar protocol in response to $\mathrm{PE}$ in aortic rings.

3.5. Effect of $\mathbf{Q 7}$ on Aortic Rings Vasoconstriction Induced by $P E$. The effect of $\mathbf{Q} 7$ preincubation on the contractility response to PE was explored. As shown in Figure 7(a), Q7 at $10^{-5} \mathrm{M}$ did not potentiate the contractile effect induced by $\mathrm{PE}$ when tested in the presence of normal KRB $\left(1.3 \times 10^{-3} \mathrm{M}\right.$ extracellular calcium). However, Q7 enhanced the contractile response to $\mathrm{PE}$ when calcium was added to extracellular space in a calcium-free medium. No change in the basal tension of aortic rings was observed by Q7 per se. We investigated if the contraction induced by $\mathrm{PE}$ in presence of $\mathbf{Q 7}$ could be modulated by calcium inflow from the extracellular space. Thus, we added increasing concentrations of $\mathrm{CaCl}_{2}$ to a calcium-free medium. Figure 7(b) shows that in the presence of $10^{-3} \mathrm{M} \mathrm{CaCl}_{2}, \mathrm{Q} 7\left(10^{-5} \mathrm{M}\right)$ significantly increased the contractile response to $\mathrm{PE}\left(10^{-6} \mathrm{M}\right)$ from $128 \pm 1 \%$ control to $158 \pm 9 \%(p<0.05)$. Percentages were determined with respect to submaximal contraction with $6 \times 10^{-2} \mathrm{M} \mathrm{KCl}$. This data suggests that $\mathbf{Q 7}$ increased calcium influx thus enhancing PE-induced vasoconstriction.

3.6. Role of Potassium Channels in the Vascular Response to Q7 in Rat Aortic Rings. The putative role of potassium channels on vascular contractile response was further studied. For this 


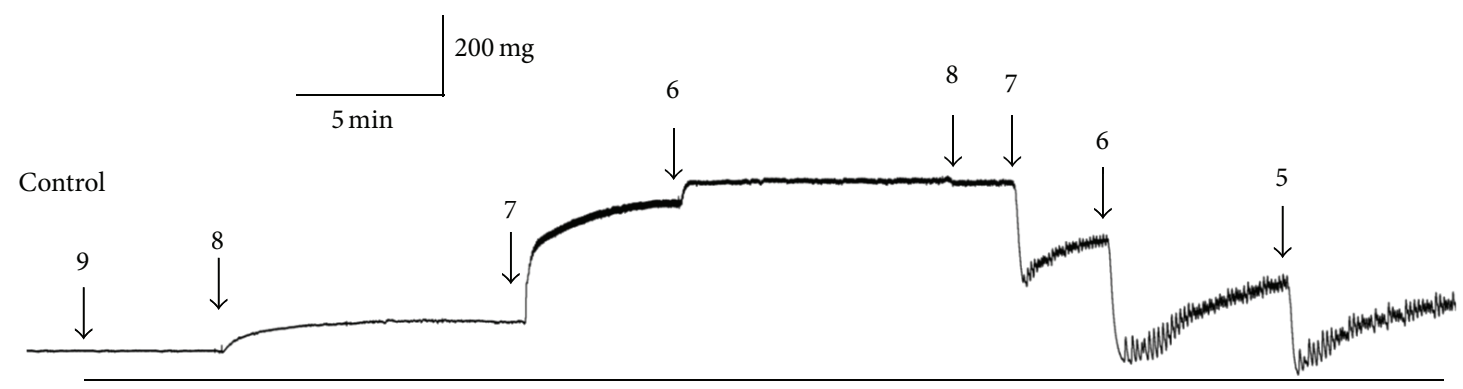

(a)

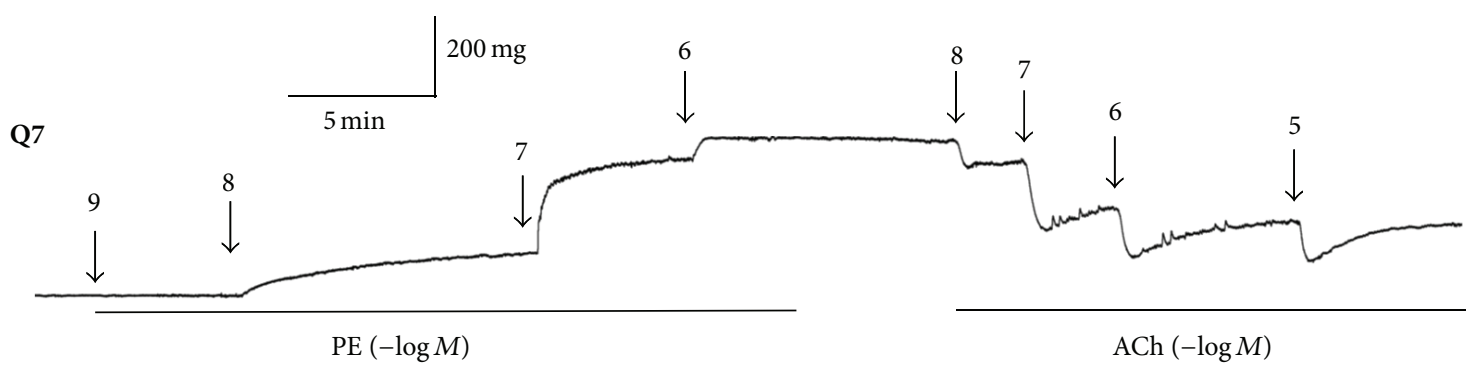

(b)

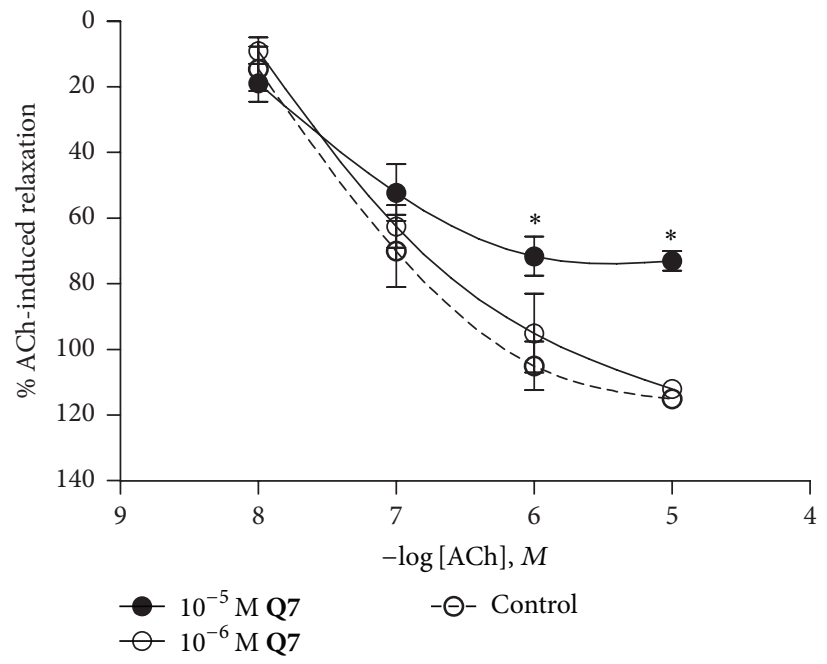

(c)

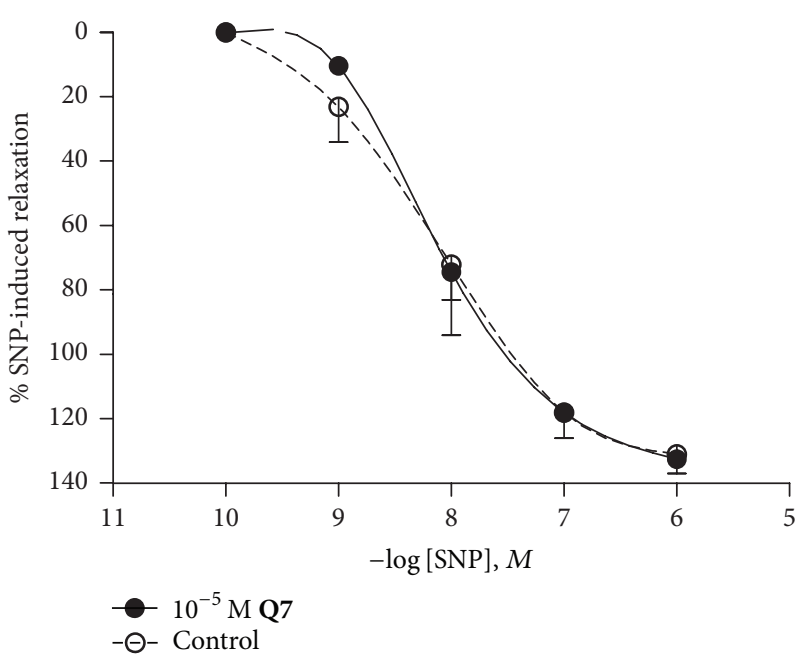

(d)

FIGURE 5: Q7 impairs ACh-induced vasodilation in an NO-dependent mechanism. Original trace showing the time course of the concentration-response curves to PE $\left(10^{-9}-10^{-6} \mathrm{M}\right)$ and $\mathrm{ACh}\left(10^{-8}-10^{-5} \mathrm{M}\right)$ in intact aortic rings of rats: control (a) and in the presence of $10^{-5} \mathrm{M}$ Q7 for $30 \mathrm{~min}(\mathrm{~b})$. After an equilibration period and before PE, the aortic rings were stabilized by two successive near-maximal contractions with $6 \times 10^{-2} \mathrm{M} \mathrm{KCl}$. ACh-response curves in endothelium-intact rat aorta in the presence or absence (control) of Q7 (10 $0^{-6} \mathrm{M}$, $\left.10^{-5} \mathrm{M}\right)(\mathrm{c})$. Arteries were preconstricted with $10^{-6} \mathrm{M}$ PE. SNP-response curves in rat aorta in the presence or absence (control) of $10^{-5} \mathrm{M} \mathrm{Q7}$ (d). Data are the average \pm SEM of $4-5$ independent experiments. ${ }^{*} p<0.05$ versus control.

purpose, $\mathrm{BaCl}_{2}$ was used, as it increases vasoconstriction by blocking voltage-dependent $\mathrm{Ca}^{2+}$-sensitive $\mathrm{K}^{+}$channels. Figure 8(a) shows that preincubation with $\mathbf{Q 7}$ significantly enhanced the contractile response to $\mathrm{BaCl}_{2}\left(10^{-3} \mathrm{M}\right): 125 \pm$ $3 \%$ control versus $161 \pm 15 \%$ with $10^{-5} \mathrm{M} \mathbf{Q 7}(p<0.05)$. Interestingly, low concentrations of $\mathrm{KCl}$ caused repolarization and decreased the vasoconstriction, but, in the presence of Q7, $10^{-2} \mathrm{M} \mathrm{KCl}$ did not decrease the vasoconstriction provoked by $\mathrm{BaCl}_{2}$. Only when a NO donor $\left(10^{-8} \mathrm{M} \mathrm{SNP}\right)$ was added to the preparation, the aortic rings were able to recover $100 \%$ of its vasodilation, reaching values similar to control conditions (Figure $8(\mathrm{~b})$ ). These data suggest that potassium channels are required for the modulatory effect of Q7 on vascular contractile response and in consequence, the compound might affect the membrane potential.

\section{Discussion}

The modulation of blood flow through the vascular endothelium influences the progression of several pathologies 


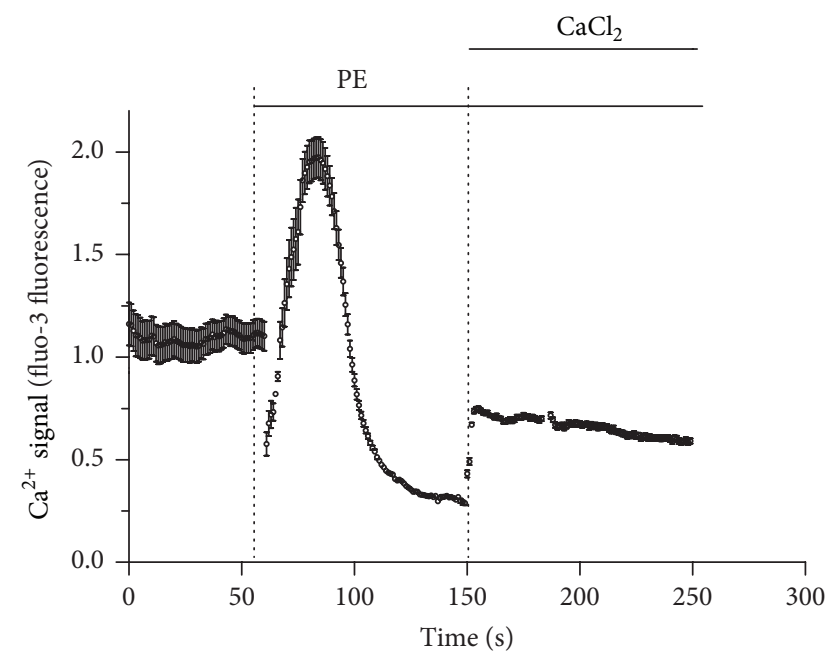

(a)

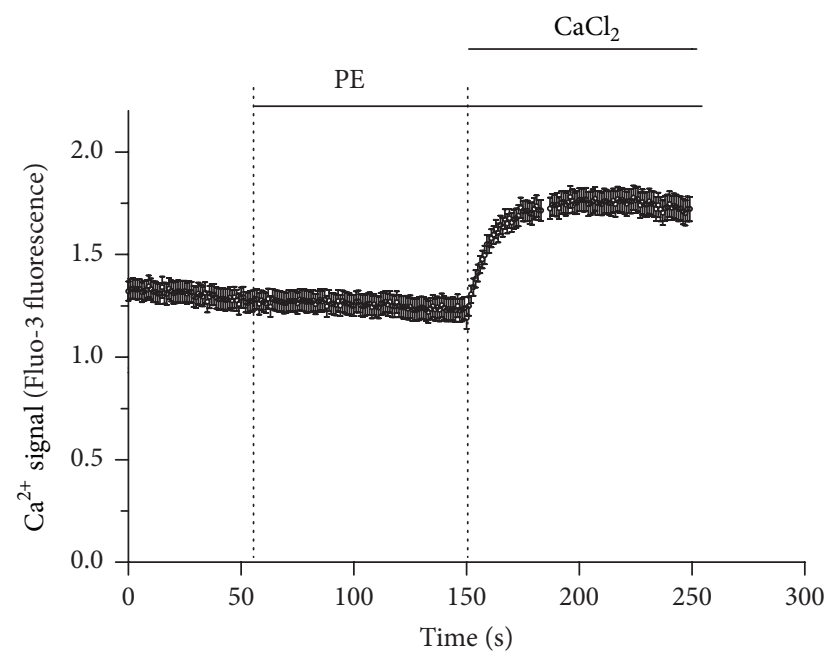

(b)

Figure 6: Quinone effect on intracellular $\mathrm{Ca}^{2+}$ levels in A7r5 cells. Q7 blunted the release of calcium from intracellular stores, but not the influx of calcium from extracellular space. Representative plots of relative changes in $\mathrm{Ca}^{2+}$ signal (fluo-3 fluorescence) over time on A7r5 cells in calcium-free medium with $10^{-6} \mathrm{M}$ phenylephrine (PE) in absence of Q7 (control) (a) or presence of $10^{-5} \mathrm{M}$ Q7 (b). Data are the average \pm $\operatorname{SEM}(n=3)$.

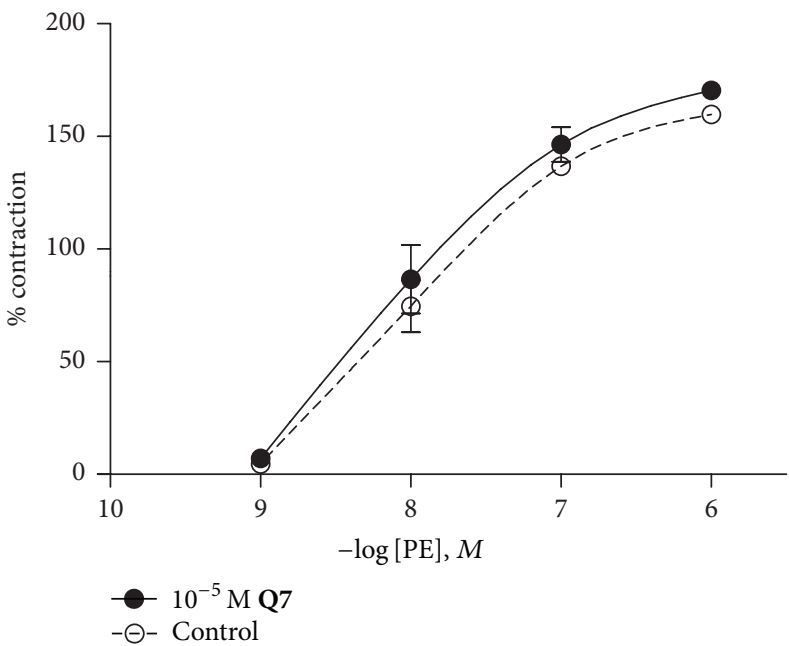

(a)

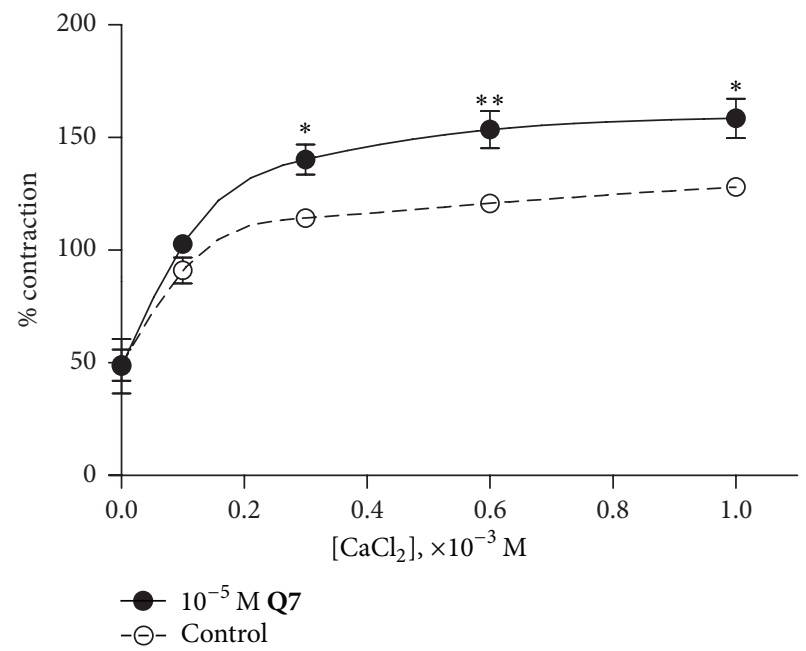

(b)

FIGURE 7: Q7 increases PE-dependent vasoconstriction in a $\mathrm{Ca}^{2+}$-dependent manner. PE-response curves in endothelium-intact rat aorta in the presence or absence (control) of $10^{-5} \mathrm{M}$ Q7 (a). The vascular tissue was preincubated in a KRB buffer without calcium for $10 \mathrm{~min}$ before $10^{-6} \mathrm{M}$ PE was added; and then, the $\mathrm{CaCl}_{2}\left(0.1,0.3,0.6\right.$, and $\left.1.0 \times 10^{-3} \mathrm{M}\right)$ was added to the bath (b). Data are the average \pm SEM of $4-5$ independent experiments. ${ }^{*} p<0.05$ and ${ }^{* *} p<0.01$ versus control.

$[36,37]$. Although studies have shown that quinone related compounds can impair vasodilation by endothelial dysfunction $[3,4,38]$, the effect of quinones on endothelial function at low concentrations is not well characterized.

We found that noncytotoxic doses of Q7 induces oxidative stress and reduces the formation of endothelial $\mathrm{NO}$ in rat aorta, thus decreasing endothelial NO-dependent vasodilation. Our findings are consistent with a probable mechanism in which oxidative stress and decrease of NO may partially block potassium channels, thus depolarizing the cell membrane leading in consequence to the opening of calcium channels, increased calcium influx, and thus increasing calcium-dependent vasoconstriction.

Herein, we show that Q7 cytotoxicity after $48 \mathrm{~h}$ on vascular endothelial cell was negligible and on vascular smooth muscle cell was low. Considering that the incubation time in experiments conducted to determine vascular reactivity and oxidative stress in rat aortic rings lasted $30 \mathrm{~min}$, it appears unlikely that such effects are the consequence of Q7 cytotoxicity. 


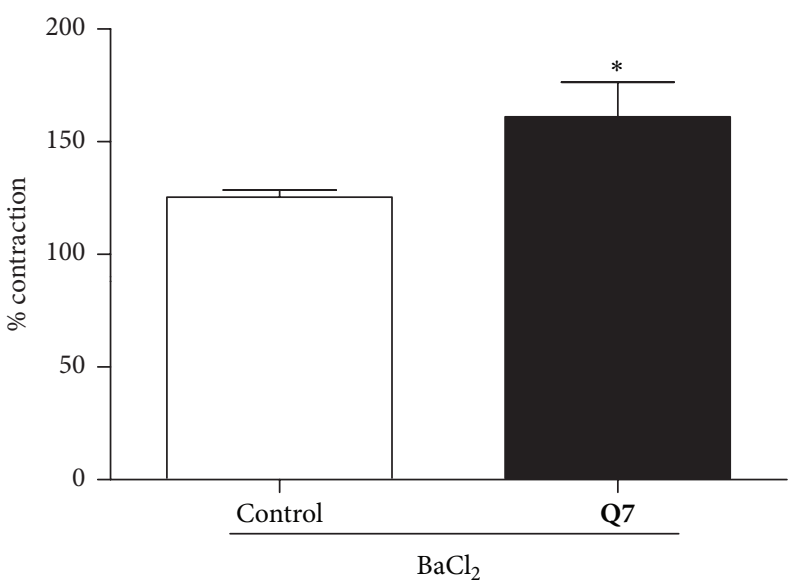

(a)

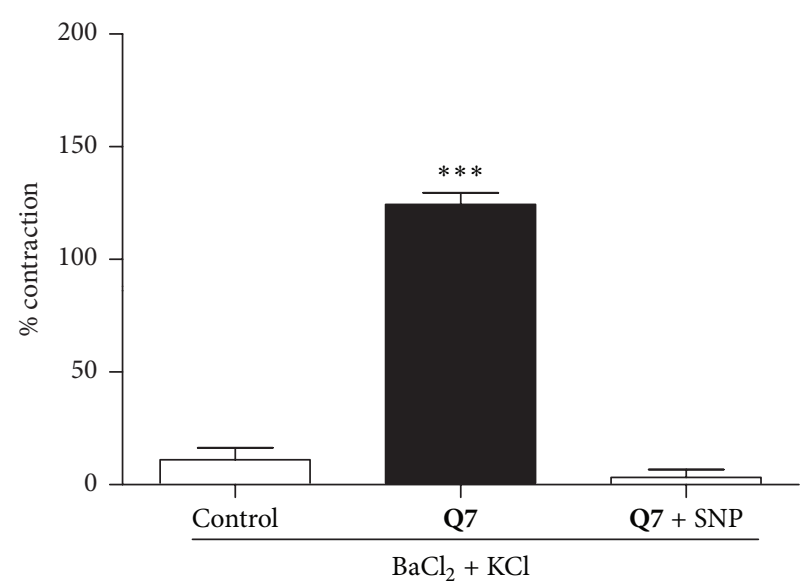

(b)

FIGURE 8: Acute effect of $\mathbf{Q 7}$ on potassium channels in rat aorta. Q7 significantly decreases the vascular contractile response involved potassium channels. The contraction with $10^{-3} \mathrm{M} \mathrm{BaCl}_{2}$ (a) and effect of $10^{-2} \mathrm{M} \mathrm{KCl}$ (b) in rat aorta precontracted with $10^{-3} \mathrm{M} \mathrm{BaCl}_{2}$ are shown. Open bar (control, vehicle), black bar $\left(10^{-5} \mathrm{M}\right.$ Q7), and striped bar $\left(10^{-5} \mathrm{M} \mathrm{Q7}^{-10^{-8}} \mathrm{M} \mathrm{SNP}\right.$. Percentages of contraction with $\mathrm{BaCl}_{2}$ were determined with respect to submaximal contraction with $6 \times 10^{-2} \mathrm{M} \mathrm{KCl}$ (a), and the percentages of contraction in presence of $10^{-2} \mathrm{M}$ $\mathrm{KCl}$ were determined with respect to maximal contraction with $10^{-3} \mathrm{M} \mathrm{BaCl}_{2}$ (b). Data are the average $\pm \mathrm{SEM}$ of 4-5 independent experiments. ${ }^{*} p<0.05$ and ${ }^{* * *} p<0.001$ versus control.

In the present study, we observed that Q7 significantly increased lipid peroxidation in rat aorta homogenates, as shown by the enhanced TBARS formation. This finding was attributed to the capacity of $\mathbf{Q 7}$ to produce oxidative stress by increasing of ROS. In previous studies, we showed that TBARS increased in calf-thymus DNA treated with Q7 or juglone [39]. Free radicals can attack DNA at C4 of deoxyribose generating products as propenal, which react with 2-thiobarbituric acid and produce the TBARS formation [40]. In both T24 and MCF-7 cells, we found that Q7 provoked elevated levels of intracellular ROS [23, 25, 35, 39].

Oxidative stress produced by $\mathbf{Q 7}$ is mainly due to ROS generation through a redox-cycling mechanism as described for other quinones [12]. This might affect critically NO levels in the rat aorta. Q7 increased the formation of L-citrulline in HUVEC, compatible with increased $\mathrm{NO}$ generation and eNOS activity [41]. This paradoxical result can be explained in part because the ROS produced by redox-cycling of $\mathbf{Q} 7$ react rapidly with generated NO, leading to a reduction of its level [38]. Quinones (i.e., doxorubicin, menadione) increase the generation of ROS (anion superoxide) leading to scavenging of NO, in agreement with previously described results [4244]. In fact, we now found that $\mathbf{Q} 7$ significantly reduced the ACh-mediated NO formation.

Accordingly, ACh-mediated endothelial vasodilation was significantly reduced by $\mathbf{Q 7}$, but it was recovered when a NO donor (SNP) was added into intact rat aorta preparations. Therefore, endothelial dysfunction caused by Q7 may be explained by a decrease in the bioavailability of endothelial NO.

Oxidative stress is associated with disruption of intracellular calcium homoeostasis [45]. In fact, Q7 blunted the release of calcium from intracellular stores in response to $\mathrm{PE}$ on vascular smooth muscle cell (A7r5 cells) in a free-calcium medium. Similar results we observed in cardiac fibroblasts preincubated with $\mathbf{Q 7}$ in a free-calcium medium in presence of angiotensin II (data not shown). These findings suggest that oxidative stress induced by Q7 blocked the release of intracellular calcium or caused calcium leakage from intracellular stores to extracellular space. This is in agreement with the inhibitory effect of quinone-related compounds (menadione) on the release of calcium from intracellular stores [46], by inhibition of sarcoplasmic calcium ATPase [47]. It is possible that the endoplasmic reticulum emptying of calcium by $\mathbf{Q} 7$ enhanced the contractile response to $\mathrm{PE}$ of aortic rings when calcium was provided extracellularly. We found that Q7 did not decrease the influx of calcium from extracellular space.

We have obtained preliminary data suggesting that Q7 may also inhibit potassium channels in neurons. Our results show an increase in action potential firing that is accompanied by increased input resistance (data no shown), an effect that could be mediated by blockade of hyperpolarizationactivated cyclic nucleotide gated (HCN) channels, that carry the Ih current [48]. However, more experiments are needed to confirm the participation of different ion channels in this.

To study a putative role of potassium channels in NO-dependent vasodilation, we use $\mathrm{BaCl}_{2}$. Barium blocks inward rectifying potassium channels such as ATP-sensitive $\mathrm{K}^{+}$channels at submillimolar concentrations $[49,50]$ and voltage-dependent $\mathrm{Ca}^{2+}$-sensitive $\mathrm{K}^{+}$channels at millimolar concentrations $[29,30]$. The result of the blockage of potassium channels by barium induced contraction in aortic rings. In the presence of Q7, the addition of $\mathrm{KCl}\left(10^{-2} \mathrm{M}\right)$ was unable to provoke a total vasodilation in rat aorta preconstricted with $\mathrm{BaCl}_{2}\left(10^{-3} \mathrm{M}\right)$, an effect which was however obtained at $100 \%$ by adding SNP $\left(10^{-8} \mathrm{M}\right)$. The increase of $\mathrm{KCl}$ over $2 \times 10^{-2} \mathrm{M}$ caused repolarization and vasodilation, 
because the membrane potential moves towards the new $\mathrm{K}^{+}$ equilibrium potential, and voltage-dependent $\mathrm{Ca}^{2+}$-sensitive $\mathrm{K}^{+}$channels are again opened $[29,41,51]$. These findings may be explained by previous studies, showing that juglone (5-hydroxy-1,4-naphthoquinone) partially blocks voltagedependent potassium channels, causing depolarization of the membrane [52].

These results agree with the idea that vasodilation induced by endothelial $\mathrm{NO}$ is due, at least in part, to a repolarization of the plasma membrane by opening voltagedependent $\mathrm{Ca}^{2+}$-sensitive $\mathrm{K}^{+}$channels [53-55] and closing of L-type $\mathrm{Ca}^{2+}$ channels [56], decreasing in this way the calcium influx $[57,58]$.

In conclusion, oxidative stress induced by $\mathbf{Q} 7$ decreases endothelial vasodilation, a process likely accompanied by decreased NO bioavailability and partial downstream blockade of potassium channels and membrane depolarization, followed by enhanced influx of calcium [59]. These findings could have interesting and potential clinical effects for a number of pathologies such as inflammatory disorders, diabetic blindness, age-related muscular degeneration, psoriasis, cardiovascular and autoimmune diseases, and cancer [60].

\section{Competing Interests}

The authors declare no conflict of interests.

\section{Acknowledgments}

Financial support by the Universidad Arturo Prat (VRIIP0198-14 to Javier Palacios) is gratefully acknowledged. This research was funded in part by Comision Nacional de Ciencia y Tecnologia (CONICYT), Chile, FONDECYT 1100376 to Jaime A. Valderrama, FONDECYT 1140970 to Gareth I. Owen, FONDECYT 1150377 to Luis Sobrevia, FONDECYT 11150083 to Fabián Pardo, BMRC 13CTI-21526P6, CORFO 13IDL3, CONICYT/FONDAP 15130011, and IMII P09/016-F. The authors thank Dr. Chukwuemeka R. Nwokocha (Department of Basic Medical Sciences Physiology Section, Faculty of Medical Sciences, University of the West Indies, Jamaica) for his helpful comments on the manuscript. The authors are grateful to Dr. Patricia Siqués and Dr. Julio Brito from Institute of Health Studies, Universidad Arturo Prat, for assistance with animals care.

\section{References}

[1] Y. Sato, "Novel link between inhibition of angiogenesis and tolerance to vascular stress," Journal of Atherosclerosis and Thrombosis, vol. 22, no. 4, pp. 327-334, 2015.

[2] J. Goveia, P. Stapor, and P. Carmeliet, "Principles of targeting endothelial cell metabolism to treat angiogenesis and endothelial cell dysfunction in disease," EMBO Molecular Medicine, vol. 6, no. 9, pp. 1105-1120, 2014.

[3] J. Y. Lee, M. Y. Lee, S. M. Chung, and J. H. Chung, "Menadioneinduced vascular endothelial dysfunction and its possible significance," Toxicology and Applied Pharmacology, vol. 161, no. 2, pp. 140-145, 1999.
[4] C.-K. Ryu, K.-H. Shin, J.-H. Seo, and H.-J. Kim, “6-Arylamino5,8-quinazolinediones as potent inhibitors of endotheliumdependent vasorelaxation," European Journal of Medicinal Chemistry, vol. 37, no. 1, pp. 77-82, 2002.

[5] B. P. V. Dantas, T. P. Ribeiro, V. L. Assis et al., "Vasorelaxation induced by a new naphthoquinone-oxime is mediated by NOsGC-cGMP pathway," Molecules, vol. 19, no. 7, pp. 9773-9785, 2014.

[6] P. Kovacic and R. Somanathan, "Recent developments in the mechanism of anticancer agents based on electron transfer, reactive oxygen species and oxidative stress," Anti-Cancer Agents in Medicinal Chemistry, vol. 11, no. 7, pp. 658-668, 2011.

[7] V. K. Tandon and S. Kumar, "Recent development on naphthoquinone derivatives and their therapeutic applications as anticancer agents," Expert Opinion on Therapeutic Patents, vol. 23, no. 9, pp. 1087-1108, 2013.

[8] S. L. de Castro, F. S. Emery, and E. N. da Silva Júnior, "Synthesis of quinoidal molecules: strategies towards bioactive compounds with an emphasis on lapachones," European Journal of Medicinal Chemistry, vol. 69, pp. 678-700, 2013.

[9] E. M. Malik and C. E. Müller, "Anthraquinones as pharmacological tools and drugs," Medicinal Research Reviews, vol. 36, no. 4, pp. 705-748, 2016.

[10] P. J. O’Brien, "Molecular mechanisms of quinone cytotoxicity," Chemico-Biological Interactions, vol. 80, no. 1, pp. 1-41, 1991.

[11] J. L. Bolton, M. A. Trush, T. M. Penning, G. Dryhurst, and T. J. Monks, "Role of quinones in toxicology," Chemical Research in Toxicology, vol. 13, no. 3, pp. 135-160, 2000.

[12] Y. Shang, C. Chen, Y. Li, J. Zhao, and T. Zhu, "Hydroxyl radical generation mechanism during the redox cycling process of 1,4naphthoquinone," Environmental Science \& Technology, vol. 46, no. 5, pp. 2935-2942, 2012.

[13] I. Wilson, P. Wardman, T.-S. Lin, and A. C. Sartorelli, "Oneelectron reduction of 2- and 6-methyl-1,4-naphthoquinone bioreductive alkylating agents," Journal of Medicinal Chemistry, vol. 29, no. 8, pp. 1381-1384, 1986.

[14] S. Sato, M. Iwaizumi, K. Handa, and Y. Tamura, "Electron spin resonance study on the mode of generation of free radicals of daunomycin, adriamycin, and carboquone in $\mathrm{NAD}(\mathrm{P}) \mathrm{H}$ microsome system," Gann, vol. 68, no. 5, pp. 603-608, 1977.

[15] N. R. Bachur, S. L. Gordon, and M. V. Gee, "A general mechanism for microsomal activation of quinone anticancer agents to free radicals," Cancer Research, vol. 38, no. 6, pp. 1745-1750, 1978.

[16] B. Prescott, "Potential antimalarial agents. Derivatives of 2chloro-1,4-naphthoquinone," Journal of Medicinal Chemistry, vol. 12, no. 1, pp. 181-182, 1968.

[17] I. Oeriu, "Relation between the chemical structure and antitubercular activity of various alpha-napththoquinone derivatives," Biokhimiia, vol. 28, pp. 380-383, 1963.

[18] E. M. Hodnett, C. Wongwiechintana, W. J. Dunn III, and P. Marrs, "Substituted 1,4-naphthoquinones vs. the ascitic sarcoma 180 of mice," Journal of Medicinal Chemistry, vol. 26, no. 4, pp. 570-574, 1983.

[19] E. J. Park, K.-J. Min, T.-J. Lee, Y. H. Yoo, Y.-S. Kim, and T. K. Kwon, " $\beta$-Lapachone induces programmed necrosis through the RIP1-PARP-AIF-dependent pathway in human hepatocellular carcinoma SK-Hepl cells," Cell Death and Disease, vol. 5, no. 5, Article ID e1231, 2014.

[20] P. B. Calderon, J. Cadrobbi, C. Marques et al., "Potential therapeutic application of the association of vitamins $\mathrm{C}$ and $\mathrm{K} 3$ in 
cancer treatment," Current Medicinal Chemistry, vol. 9, no. 24, pp. 2271-2285, 2002.

[21] B. P. Awasthi, M. Kathuria, G. Pant, N. Kumari, and K. Mitra, "Plumbagin, a plant-derived naphthoquinone metabolite induces mitochondria mediated apoptosis-like cell death in Leishmania donovani: an ultrastructural and physiological study," Apoptosis, vol. 21, no. 8, pp. 941-953, 2016.

[22] S.-J. Kim, J. M. Kim, S. H. Shim, and H. I. Chang, "Shikonin induces cell cycle arrest in human gastric cancer (AGS) by early growth response 1 (Egr1)-mediated p21 gene expression," Journal of Ethnopharmacology, vol. 151, no. 3, pp. 1064-1071, 2014.

[23] K. B. Felipe, J. Benites, C. Glorieux et al., "Antiproliferative effects of phenylaminonaphthoquinones are increased by ascorbate and associated with the appearance of a senescent phenotype in human bladder cancer cells," Biochemical and Biophysical Research Communications, vol. 433, no. 4, pp. 573578, 2013.

[24] R. F. Silver and H. L. Holmes, "Synthesis of some 1,4naphthoquinones and reactions relating to their use in the study of bacterial growth inhibition," Canadian Journal of Chemistry, vol. 46, no. 11, pp. 1859-1864, 1968.

[25] F. Ourique, M. R. Kviecinski, G. Zirbel et al., "In vivo inhibition of tumor progression by 5 hydroxy-1,4-naphthoquinone (juglone) and 2-(4-hydroxyanilino)-1,4-naphthoquinone (Q7) in combination with ascorbate," Biochemical and Biophysical Research Communications, vol. 477, no. 4, pp. 640-646, 2016.

[26] J.-A. Lee, S.-H. Jung, M. K. Bae et al., "Pharmacological effects of novel quinone compounds, 6-(fluorinated- phenyl)amino5,8-quinolinediones, on inhibition of drug-induced relaxation of rat aorta and their putative action mechanism," General Pharmacology, vol. 34, no. 1, pp. 33-42, 2000.

[27] A. C. Montezano and R. M. Touyz, "Reactive oxygen species, vascular noxs, and hypertension: focus on translational and clinical research," Antioxidants and Redox Signaling, vol. 20, no. 1, pp. 164-182, 2014.

[28] V. B. Marques, T. B. Nascimento, R. F. Ribeiro et al., "Chronic iron overload in rats increases vascular reactivity by increasing oxidative stress and reducing nitric oxide bioavailability," Life Sciences, vol. 143, pp. 89-97, 2015.

[29] Y. Huang, "BaCl2- and 4-aminopyridine-evoked phasic contractions in the rat vas deferens," British Journal of Pharmacology, vol. 115, no. 5, pp. 845-851, 1995.

[30] B. Rudy, "Diversity and ubiquity of K channels," Neuroscience, vol. 25, no. 3, pp. 729-749, 1988.

[31] E. A. Ko, J. Han, I. D. Jung, and W. S. Park, "Physiological roles of $\mathrm{K}+$ channels in vascular smooth muscle cells," Journal of Smooth Muscle Research, vol. 44, no. 2, pp. 65-81, 2008.

[32] G. J. M. den Hartog, A. W. Boots, G. R. M. M. Haenen, W. J. F. van der Vijgh, and A. Bast, "Lack of inhibition of endothelial nitric oxide synthase in the isolated rat aorta by doxorubicin," Toxicology in Vitro, vol. 17, no. 2, pp. 165-167, 2003.

[33] G. E. Mann, D. L. Yudilevich, and L. Sobrevia, "Regulation of amino acid and glucose transporters in endothelial and smooth muscle cells," Physiological Reviews, vol. 83, no. 1, pp. 183-252, 2003.

[34] M. González, V. Gallardo, N. Rodríguez et al., "Insulin-stimulated L-arginine transport requires SLC7A1 gene expression and is associated with human umbilical vein relaxation," Journal of Cellular Physiology, vol. 226, no. 11, pp. 2916-2924, 2011.
[35] J. Benites, J. A. Valderrama, K. Bettega, R. C. Pedrosa, P. B. Calderon, and J. Verrax, "Biological evaluation of donoracceptor aminonaphthoquinones as antitumor agents," European Journal of Medicinal Chemistry, vol. 45, no. 12, pp. 60526057, 2010.

[36] R. Ross, "The pathogenesis of atherosclerosis: a perspective for the 1990s," Nature, vol. 362, no. 6423, pp. 801-809, 1993.

[37] A. Cecchettini, S. Rocchiccioli, C. Boccardi, and L. Citti, "Vascular smooth-muscle-cell activation. proteomics point of view," International Review of Cell and Molecular Biology, vol. 288, pp. 43-99, 2011.

[38] J.-J. Kang, P.-J. Lee, Y.-J. Chen et al., "Naphthazarin and methylnaphthazarin cause vascular dysfunction by impairment of endothelium-derived nitric oxide and increased superoxide anion generation," Toxicology in Vitro, vol. 20, no. 1, pp. 43-51, 2006.

[39] F. Ourique, M. R. Kviecinski, K. B. Felipe et al., "DNA damage and inhibition of akt pathway in MCF-7 cells and ehrlich tumor in mice treated with 1,4-naphthoquinones in combination with ascorbate," Oxidative Medicine and Cellular Longevity, vol. 2015, Article ID 495305, 10 pages, 2015.

[40] Q. Jiang, N. Xiao, P. Shi, Y. Zhu, and Z. Guo, "Design of artificial metallonucleases with oxidative mechanism," Coordination Chemistry Reviews, vol. 251, no. 15-16, pp. 1951-1972, 2007.

[41] F. Cifuentes, J. Palacios, and C. R. Nwokocha, "Synchronization in the heart rate and the vasomotion in rat aorta: effect of arsenic trioxide," Cardiovascular Toxicology, vol. 16, no. 1, pp. 79-88, 2016.

[42] J. Vásquez-Vivar, P. Martasek, N. Hogg, B. S. S. Masters, K. A. Pritchard Jr., and B. Kalyanaraman, "Endothelial nitric oxide synthase-dependent superoxide generation from adriamycin," Biochemistry, vol. 36, no. 38, pp. 11293-11297, 1997.

[43] O.-N. Bae, K.-M. Lim, J.-Y. Han et al., "U-shaped dose response in vasomotor tone: a mixed result of heterogenic response of multiple cells to xenobiotics," Toxicological Sciences, vol. 103, no. 1, pp. 181-190, 2008.

[44] C. Gerassimou, A. Kotanidou, Z. Zhou, D. D. C. Simoes, C. Roussos, and A. Papapetropoulos, "Regulation of the expression of soluble guanylyl cyclase by reactive oxygen species," British Journal of Pharmacology, vol. 150, no. 8, pp. 1084-1091, 2007.

[45] G. Ermak and K. J. Davies, "Calcium and oxidative stress: from cell signaling to cell death," Molecular Immunology, vol. 38, no. 10, pp. 713-721, 2002.

[46] N. Dejeans, N. Tajeddine, R. Beck et al., "Endoplasmic reticulum calcium release potentiates the ER stress and cell death caused by an oxidative stress in MCF-7 cells," Biochemical Pharmacology, vol. 79, no. 9, pp. 1221-1230, 2010.

[47] D. Di Monte, G. Bellomo, H. Thor, P. Nicotera, and S. Orrenius, "Menadione-induced cytotoxicity is associated with protein thiol oxidation and alteration in intracellular $\mathrm{Ca}^{2+}$ homeostasis," Archives of Biochemistry and Biophysics, vol. 235, no. 2, pp. 343-350, 1984.

[48] S. B. Williams and J. J. Hablitz, "Differential modulation of repetitive firing and synchronous network activity in neocortical interneurons by inhibition of A-type K+ channels and Ih," Frontiers in Cellular Neuroscience, vol. 9, article 89, 2015.

[49] U. Quast, "Do the $\mathrm{K}^{+}$channel openers relax smooth muscle by opening $\mathrm{K}^{+}$channels?" Trends in Pharmacological Sciences, vol. 14, no. 9, pp. 332-337, 1993.

[50] N. B. Standen, J. M. Quayle, N. W. Davies, J. E. Brayden, Y. Huang, and M. T. Nelson, "Hyperpolarizing vasodilators 
activate ATP-sensitive $\mathrm{K}^{+}$channels in arterial smooth muscle," Science, vol. 245, no. 4914, pp. 177-180, 1989.

[51] K. A. Dora, N. T. Ings, and C. J. Garland, "KCa channel blockers reveal hyperpolarization and relaxation to $\mathrm{K}+$ in rat isolated mesenteric artery," American Journal of Physiology-Heart and Circulatory Physiology, vol. 283, no. 2, pp. H606-H614, 2002.

[52] Z. Varga, L. Bene, C. Pieri, S. Damjanovich, and R. Gáspár, “The effect of juglone on the membrane potential and whole-cell $\mathrm{K}^{+}$ currents of human lymphocytes," Biochemical and Biophysical Research Communications, vol. 218, no. 3, pp. 828-832, 1996.

[53] S. L. Archer, J. M. C. Huang, V. Hampl, D. P. Nelson, P. J. Shultz, and E. K. Weir, "Nitric oxide and cGMP cause vasorelaxation by activation of a charybdotoxin-sensitive K channel by cGMPdependent protein kinase," Proceedings of the National Academy of Sciences of the United States of America, vol. 91, no. 16, pp. 7583-7587, 1994.

[54] M. E. Murphy and J. E. Brayden, "Nitric oxide hyperpolarizes rabbit mesenteric arteries via ATP-sensitive potassium channels," The Journal of Physiology, vol. 486, no. 1, pp. 47-58, 1995.

[55] Y. J. Zhao, J. Wang, L. J. Rubin, and X. J. Yuan, "Inhibition of $\mathrm{K}(\mathrm{V})$ and $\mathrm{K}(\mathrm{Ca})$ channels antagonizes NO-induced relaxation in pulmonary artery," American Journal of Physiology, vol. 272, no. 2, part 2, pp. H904-H912, 1997.

[56] V. Ruiz-Velasco, J. Zhong, J. R. Hume, and K. D. Keef, "Modulation of $\mathrm{Ca} 2+$ channels by cyclic nucleotide cross activation of opposing protein kinases in rabbit portal vein," Circulation Research, vol. 82, no. 5, pp. 557-565, 1998.

[57] P. J. Barnes and S. F. Liu, "Regulation of pulmonary vascular tone," Pharmacological Reviews, vol. 47, no. 1, pp. 87-131, 1995.

[58] S. A. Khan, N. R. Higdon, and K. D. Meisheri, "Coronary vasorelaxation by nitroglycerin: involvement of plasmalemmal calcium-activated $\mathrm{K}+$ channels and intracellular $\mathrm{Ca}++$ stores," Journal of Pharmacology and Experimental Therapeutics, vol. 284, no. 3, pp. 838-846, 1998.

[59] J. V. Gerasimenko, O. V. Gerasimenko, A. Palejwala, A. V. Tepikin, O. H. Petersen, and A. J. M. Watson, "Menadioneinduced apoptosis: roles of cytosolic $\mathrm{Ca}^{2+}$ elevations and the mitochondrial permeability transition pore," Journal of Cell Science, vol. 115, no. 3, pp. 485-497, 2002.

[60] E. Aranda and G. I. Owen, "A semi-quantitative assay to screen for angiogenic compounds and compounds with angiogenic potential using the EA.hy926 endothelial cell line," Biological Research, vol. 42, no. 3, pp. 377-389, 2009. 


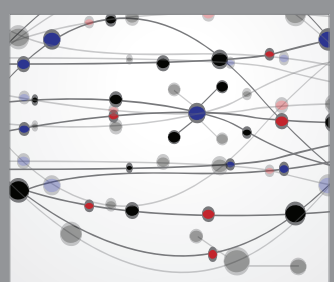

The Scientific World Journal
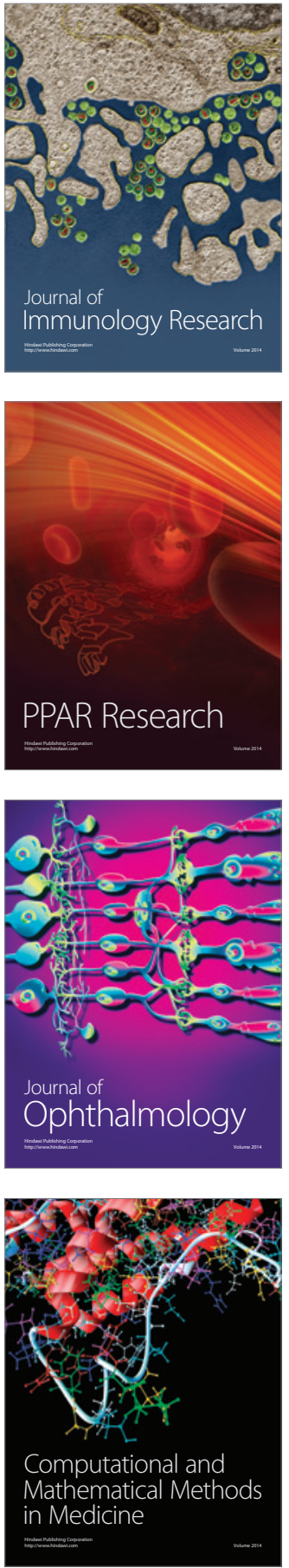

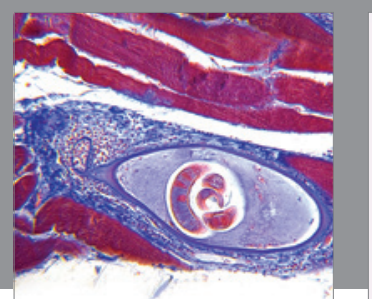

Gastroenterology Research and Practice

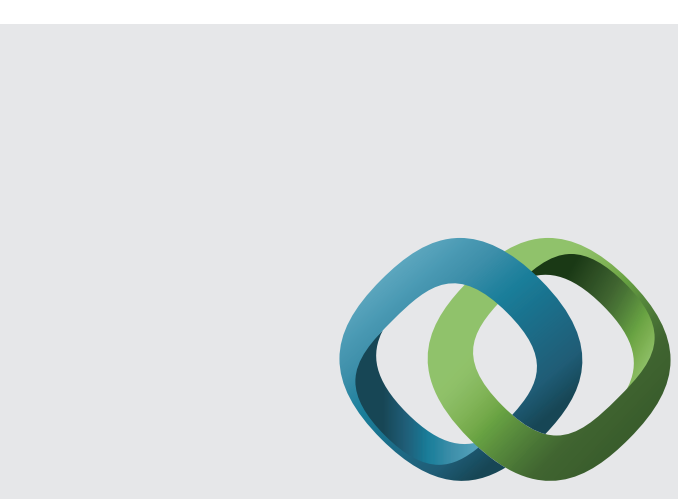

\section{Hindawi}

Submit your manuscripts at

http://www.hindawi.com
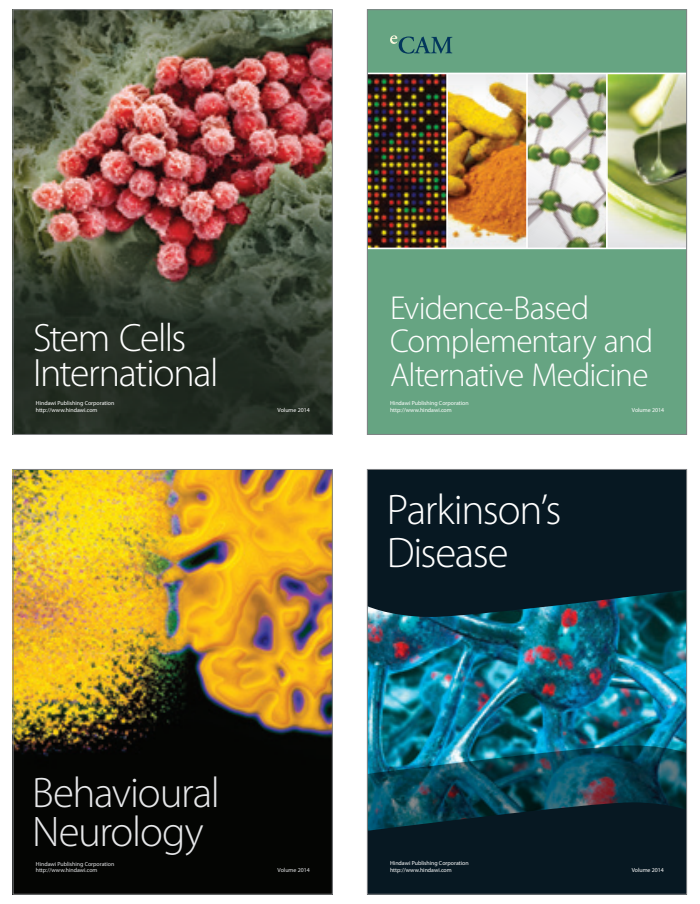
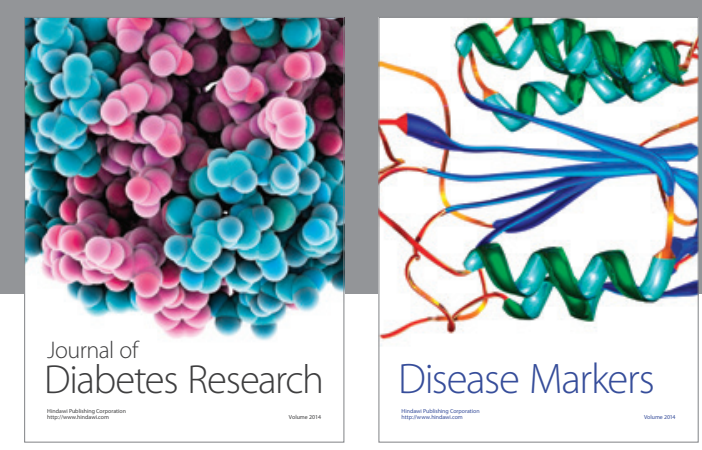

Disease Markers
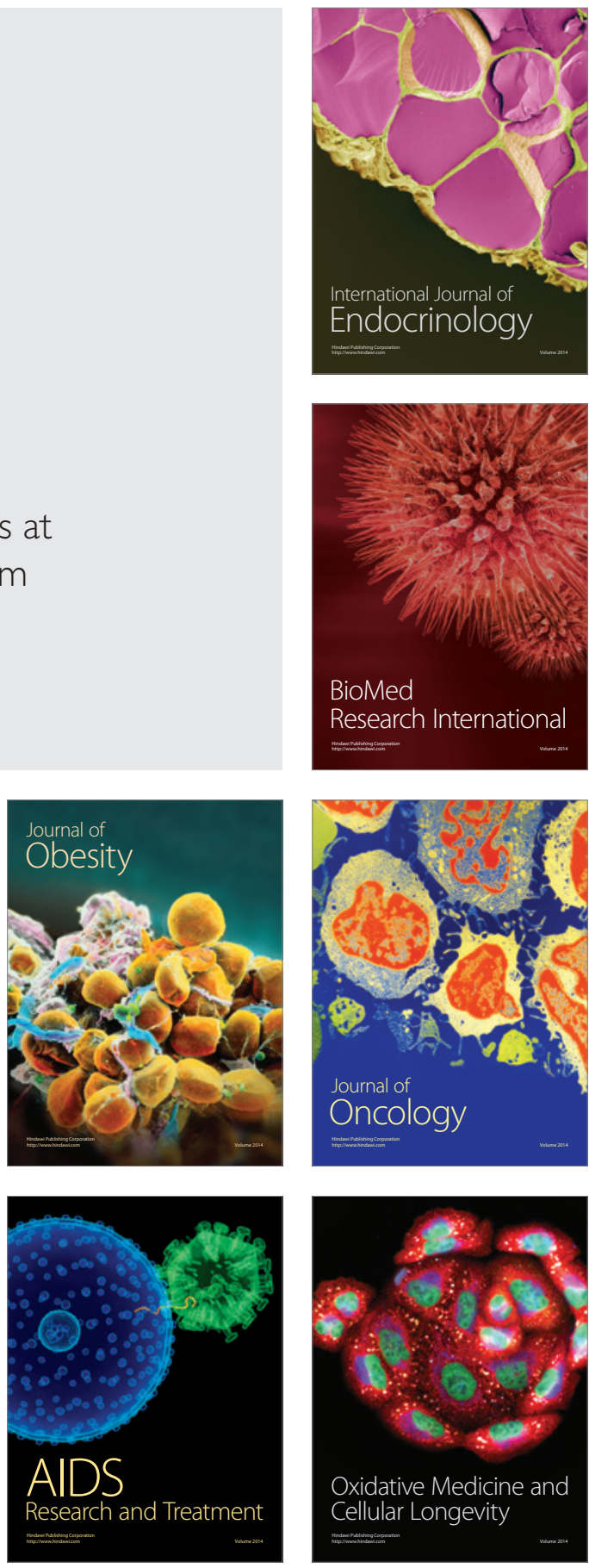